\title{
FEES FROZEN BUT COMPLAINTS INVESTIGATED
}

The General Dental Council (GDC) has announced that there were will be no increase in the annual retention fee (ARF) in 2012 for either dentists or dental care professionals (DCPs).

This means that dentists will pay £576 by 31 December 2011 and DCPs will pay £120 by 31 July 2012.

The decision to keep the fee at 2011 levels is in line with both the GDC's own strategy and the Government's Command Paper Enabling Excellence, ensuring GDC resources are managed effectively, efficiently and sustainably.

Meanwhile Dr Alison Lockyer, who resigned both as a member and Chair of the GDC in May, has welcomed the news that the Council for Healthcare Regulatory Excellence (CHRE) is to investigate the concerns she raised following her resignation.

In May Dr Lockyer wrote to the Secretary of State for Health raising a concern over the relationship between the appointed Council and the Executive of the GDC and the way the dental profession is currently regulated. Dr Lockyer's second concern questioned the suitability of the GDC's own internal procedures to deal with complaints made against one of its officers.

In welcoming the news that these complaints will be investigated, Dr Lockyer has asked colleagues to understand that she is unable to make any further comment on this matter while the CHRE undertakes its investigation.

\section{HOLISTIC APPROACH TO BRUXISM-RELATED MIGRAINE}

Cosmetic dental practitioner Dr Biju Krishnan and physiotherapy expert Kirsten Lord have teamed up to create an innovative Migraine Relief Clinic to treat those suffering from migraines usually caused by bruxism.

As part of the treatment, patients are fitted with a specific and discrete Nociceptive Trigeminal Inhibition (NTI) splint which is worn at night on either the upper or lower front teeth. Patients also undergo individual physiotherapy treatments to release and loosen muscles that may be involved in triggering a migraine attack.

'Studies have shown that the NTI splint which we fit is highly successful in decreasing stress in the jaw and reducing migraine pain attacks by up to 75\% in 75\% of users,' said Dr Krishnan, who owns Lubiju dental practice in Edinburgh. The splint can 'also prevent tooth damage and in some patients has been shown to reduce problems associated with snoring,

Combining the treatment with a course of physiotherapy is designed to prove a much more effective and longer lasting solution for patients. Kirsten and her physiotherapy team are involved from the beginning of the consultation process.

'So far the treatment programme has been extremely successful and we have treated over 250 patients, who have all seen significant improvement as a result,' said Dr Krishnan.

The package of treatment offered includes three physiotherapy sessions at the Edinburgh or Glasgow Physiotherapy Centres and the fitting of the NTI splint at Lubiju.

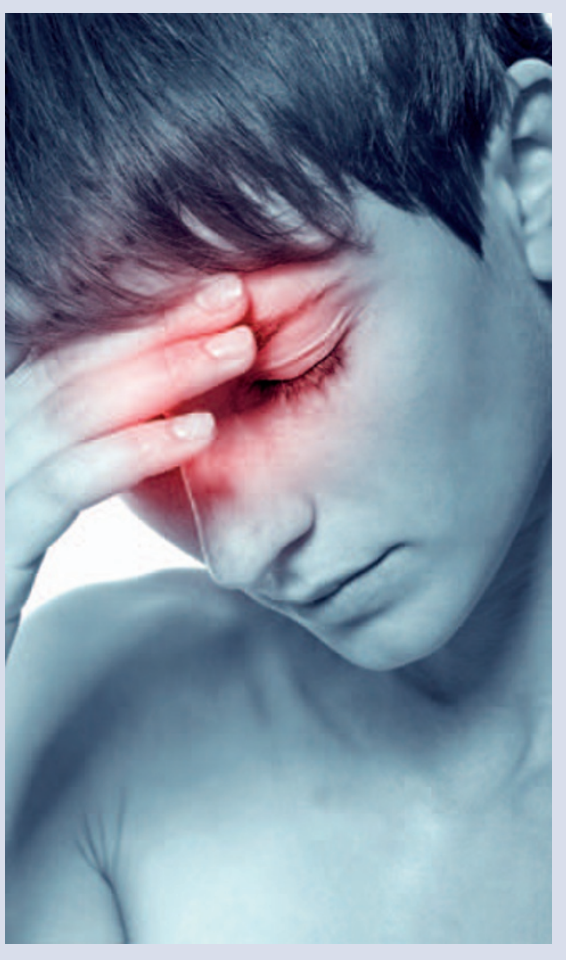

